\title{
O efeito do uso de medicamentos biológicos na qualidade de vida de pacientes com psoríase moderada a grave: uma revisão da literatura
}

Mauricio Alexandre de Almeida TELLES: Faculdade de Saúde Pública - FSP, Universidade de São Paulo - USP. ORCID: https://orcid.org/0000-0001-6509-2725

Samara Jamile MENDES: Faculdade de Saúde Pública - FSP, Universidade de São Paulo - USP. ORCID: https://orcid.org/0000-0003-3107-8233

Recebido: 2 out. 2020 Aceito: 21 out. 2020

Autor de correspondência: Maurício Alexandre de Almeida Telles telles_mauricio@hotmail.com

Conflito de interesses: Os autores declaram não haver nenhum interesse profissional ou pessoal que possa gerar conflito de interesses em relação a este manuscrito.

\section{Resumo}

A psoríase é uma doença cutânea comum, crônica e não transmissível, sem causa clara ou cura. $\mathrm{O}$ impacto negativo desta condição sobre as vidas das pessoas pode ser imenso. A psoríase afeta pessoas de todas as idades, e em todos os países. É importante levar em consideração alguns fatos, a psoríase afeta pessoas de todas as idades, e em todos os países. A prevalência relatada nos países varia entre 0,09\% e 11,43\%, o que torna a psoríase um problema global sério, com no mínimo 100 milhões de indivíduos afetados mundialmente. A psoríase apresenta uma evolução dos sintomas imprevisível, uma diversidade de gatilhos externos e comorbidades significativas, incluindo artrite, doenças cardiovasculares, síndrome metabólica, doença intestinal inflamatória e depressão. A OMS reconhece a psoríase como uma doença não transmissível (NCD) séria, destacando que muitas pessoas no mundo sofrem sem necessidade em virtude do diagnóstico incorreto ou tardio, de opções de tratamento inadequadas e do acesso insuficiente aos cuidados, e em virtude da estigmatização social, a psoríase causa um grande ônus físico, emocional e social. Há a necessidade de um debate central quando fala-se em psoríase: Para estes pacientes é de fato um ponto de extrema relevância, qualidade de vida é uma noção eminentemente humana, que tem sido aproximada ao grau de satisfação encontrado na vida familiar, amorosa, social e ambiental e à própria estética existencial. Pressupõe a capacidade de efetuar uma síntese cultural de todos os elementos que determinada sociedade considera seu padrão de conforto e bem-estar. O termo abrange muitos significados, que refletem conhecimentos, experiências e valores de indivíduos e coletividades que a ele se reportam em variadas épocas, espaços e histórias diferentes, sendo, portanto, uma construção social com a marca da relatividade cultural. Desde 2010 anos foram lançados tratamentos biológicos focados na Psoriase Moderada a Grave com o objetivo de maior eficácia e promoção de melhora na qualidade de vida dos pacientes. Maior eficácia quer dizer que as lesões dos pacientes serão eliminadas em maior proporção passando de uma escala PASI75 para PASI90, onde PASI significa Psoriasis Área and Severity Index (PASI). Os agentes biológicos são moléculas de natureza proteica, semelhantes a proteínas animais ou humanos, sendo susceptíveis à digestão no trato gastrointestinal. Apresentam tamanho molecular relativamente grande, sendo, por isso, administradas por via parenteral (subcutânea, intramuscular ou intravenosa) e não oral. São proteínas recombinantes, criadas por engenharia genética, que podem ser anticorpos monoclonais, proteínas de fusão ou citocinas humanas recombinantes. Revisar a literatura cientifica sobre o uso de medicamentos biológicos na qualidade de vida de pacientes com 
psoríase. O presente trabalho é uma revisão integrativa da literatura sobre os medicamentos biológicos para o tratamento da Psoríase moderada a grave e seus impactos na qualidade de vida destes pacientes. Foi realizada uma pesquisa exploratória a partir das bases de dados disponíveis na Biblioteca Virtual em Saúde Pública - BVS (Lilacs e Sistema Online de Busca e Análise de Literatura Médica - Medline). A definição de descritores para a busca foi realizada a partir da pergunta de pesquisa, permitindo a formulação das sintaxes para encontrar a literatura adequada para a revisão proposta. A pergunta de pesquisa utilizada para nortear esta revisão foi: $\mathrm{O}$ impacto da psoríase moderada a grave na qualidade de vida dos pacientes antes e depois do uso de medicamentos Biológicos? A busca bibliográfica foi realizada a partir da combinação dos descritores $A$ composição sintática realizada do tema parte da compreensão de três eixos temáticos (descritores principais) identificados a partir da pergunta da pesquisa: Psoríase; Qualidade de Vida; Biológicos. As combinações foram realizadas com os sinônimos. psoríase: Psoríase Pustular de palmas e plantas dos pés, Pustulose Palmoplantar, Pustulose de palmas, plantas dos pés, Artrite Psoriásica, psoríase artropática, psoríase artropática. Para qualidade de vida: $\mathrm{HRQOL}$, QVRS, Qualidade de Vida Relacionada à Saúde e o próprio termo Qualidade de vida. Para biológicos: Biofarmácos, drogas biológicas, medicamentos biológicos, produtos biológicos, produtos biofarmacêuticos, remédios biológicos e imunomodulador. Após estes achados realizou-se as combinações tanto na BVS quanto no PubMed e Scielo e foram compostas sintaxes com os operadores booleanos "OR" e "AND". As possibilidades de síntese foram ordenadas. Sendo que nesta fase optou-se por incluir a base de dados Pubmed na busca e foi adicionado o filtro "Ensaios Clínicos Controlados" para um melhor direcionamento nas pesquisas. Sintaxes utilizadas: BVS: (tw:(psoriasis)) AND (tw:(quality of life)) AND (tw:(biologic)) + filtro - Ensaios Clínicos Controlados = 121 estudos (tw:(psoríase)) AND (tw:(qualidade de vida)) AND (tw:(biológico)) + Filtro - Ensaios clínicos controlados $=36$ estudos. PubMed: ((psoriasis) AND (quality of life)) AND (biologic*) + filtro - Randomized controlled trials $=40$ estudos (((psoriasis) AND (quality of life)) AND (biologic*)) AND (brazil) + Filtro - randomized controlled trials $=0$. Scielo: (psoriasis) AND (quality of life) AND $\left(\right.$ biologic $\left.{ }^{*}\right)=14$ estudos; $($ psoríase) AND (qualidade de vida) AND (biológico) $=1$ estudo. Chegou-se a 210 resultados identificados, sendo que 62 foram retirados por serem duplicados. Posteriormente será realizada a leitura de títulos e resumos, incluindo os artigos que correspondam a psoríase, qualidade de Vida e medicamentos biológicos e serão excluídos artigos de outras línguas que não inglês, espanhol e português, além de artigos que tratem apenas dos medicamentos.

Descritores: Psoríase; Qualidade de Vida; Medicamentos Biológicos.

Keywords: Psoriasis; Quality of Life; Biological Products.

Palabras-claves: Psoriasis; Calidad de Vida; Medicamentos Biológicos. 